\title{
Raman Microscopy in the Service of Industry
}

Jack Yarwood, Peter Eaton, Christopher Constable, Delphine Bard, Paul Whelan, Damien Larroumet and Chang Sheng Deng

\section{Materials Research Institute, Sheffield Hallam University, City Campus, Howard Street, Sheffield, UK}

Abstract

Raman systems have now been developed to the stage where problems of real industrial interest and importance maybe tackled with a high level of success. This paper describes some of the applications which we have made in collaboration with several companies over the last 5 years.

Migration of adhesive to a $\mathrm{PVC} / \mathrm{SiO}_{2}$ interface

Diffusion of a 'primer' towards a glass/polymer interface is obviously of importance for the production of functional glass. The Raman technique provides a convenient way to monitor such 'migration' under different conditions or for different chemical components. Relative depth profiles for the distribution of Y9669 $\left(\mathrm{C}_{6} \mathrm{H}_{5} \mathrm{NH}(-\right.$ $\left.\mathrm{CH}_{2}\right)_{3} \mathrm{Si}(\mathrm{OMe})_{3}$ in $\mathrm{PVC}$ (at equilibrium) for different thermal cycles (at $\left.70^{\circ} \mathrm{C}\right)$. We describe[1] the effects of PVC plasticization; primer chemical type and humidity on such distribution data.

We report our work[2,3] on the identification and quantification of asbestos fibres (fig 1) and carbon particulates (coal dust or diesel deposits) (fig 2) in industrial work place environments and materials. In both cases there is a strong link to health and safety regulations, via health hazard legislation.

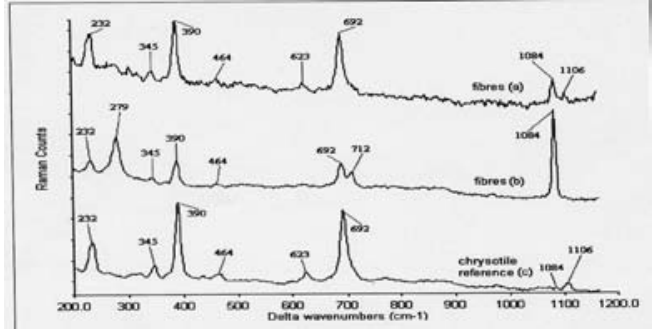

Figure 1 Raman spectra of asbestos in cement

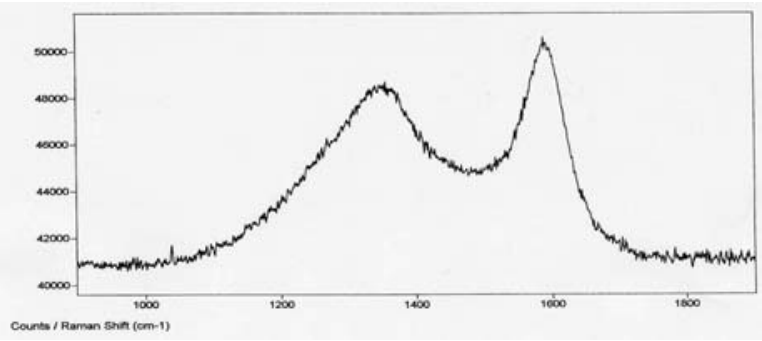

Figure 2 Raman spectra of a mixture of coal dust and DPM

3 In situ corrosion monitoring at the metal/aqueous interface

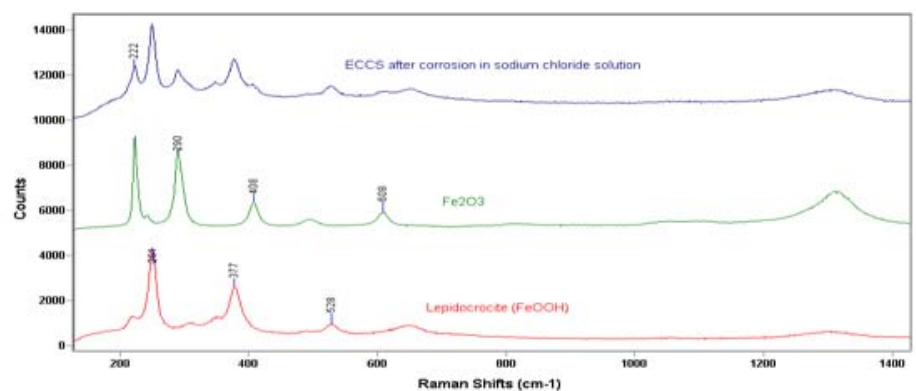

Figure 3 Formation of oxides of iron at $\mathrm{Fe} / \mathrm{H}_{2} \mathrm{O} / \mathrm{NaCl}$ interface
Figure 3 shows that we have been able to observe[4] the production of iron oxides (in situ) at an iron-wire surface which may be biased at a given voltage. The potential to do Raman-based electro-chemical monitoring at the interface is demonstrated, with our most recent data. 


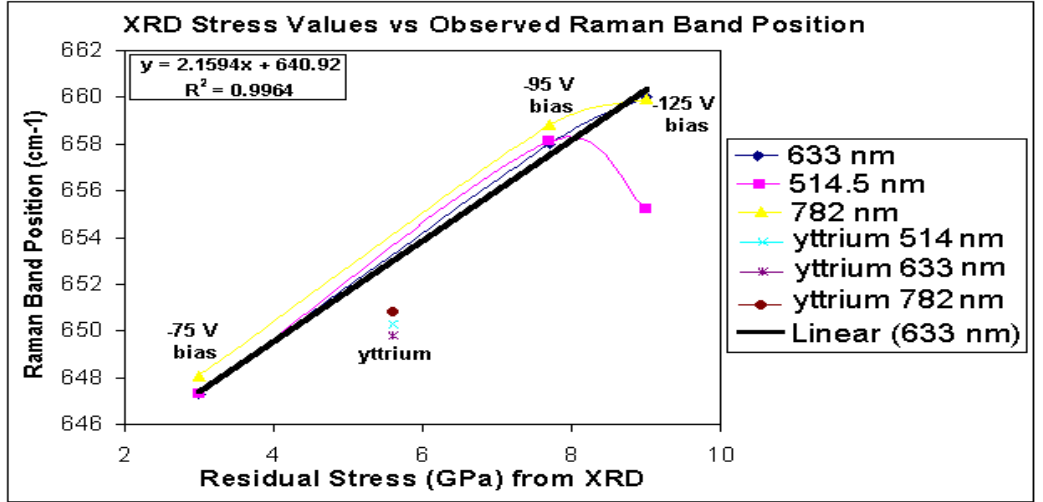

Figure 4 Calibration of Raman shifts against residual stress from XRD

The setting of oil field cement - a Raman approach.

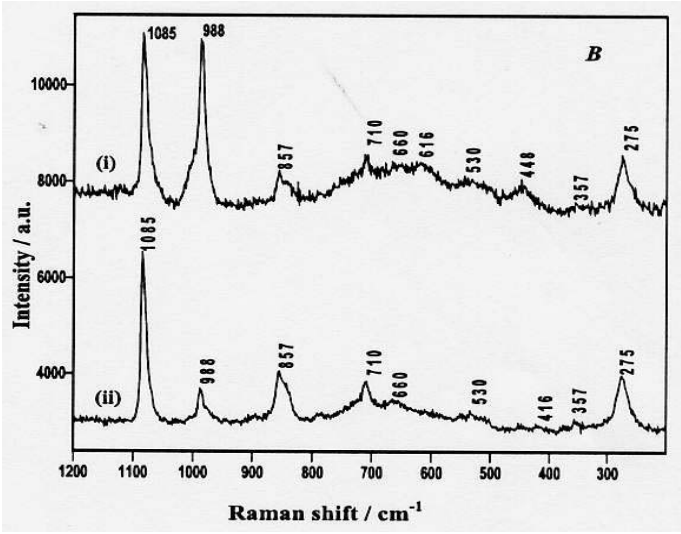

The observed Raman shifts of the principal optical phonon mode of TiAlN/VN superlattice coatings at $650 \mathrm{~cm}^{-1}$ (see fig 4) [5] have enabled us to monitor the residual stress in such coatings under different deposition conditions. Our reported results show the comparison with XRD data and the link to coating properties such as hardness, adhesion and wear.

Figure 5 Calibration of Raman shifts against residual stress from XRD

\section{References}

[1] P Eaton, P Holmes and J Yarwood, Appl. Spectrosc., 54, 508 (2000)

[2] D Bard, J Yarwood and B Tylee, J. Raman Spectr. 28, 803 (1997)

[3] Paul Whelan, PhD Thesis, Sheffield Hallam University, (2001)

[4] D Larroumet, R Akid, D Greenfield and J Yarwood (unpublished)

[5] C P Constable, B Lewis, J Yarwood and W D Münz, Surf. Coatings Techn. 2003 (in press).

[6] C S Deng, C Breen, J Yarwood, S Habesch, B Craster, G Maitland and J Phipps, J. Mat. Chem., 12, 3105 (2002)

Acknowledgements. Thanks are due to EPSRC for equipment grants and to Renishaw, Pilkington and Health and Safety Laboratory for financial support. The support of colleagues Chris Breen, Bob Akid, Barry Tylee, Brian Lewis and Dieter Münz is acknowledged. 